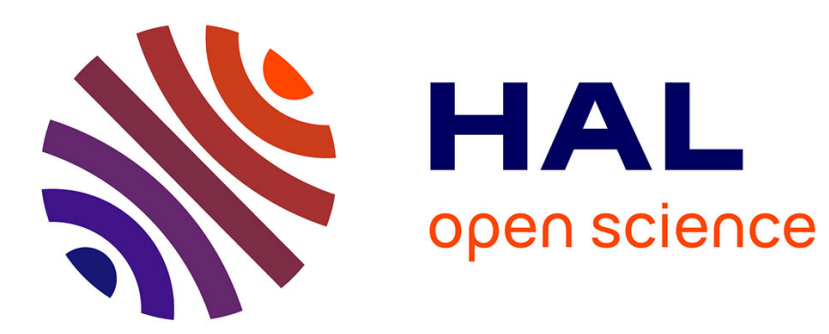

\title{
Dreams of time, times of dreams: stories of creation from roleplaying game sessions \\ Jerzy Kociatkiewicz
}

\section{To cite this version:}

Jerzy Kociatkiewicz. Dreams of time, times of dreams: stories of creation from roleplaying game sessions. Studies in Cultures, Organizations, and Societies, 2000, 6 (1), pp.71-86. 10.1080/10245280008523538. hal-02423786

\section{HAL Id: hal-02423786 \\ https://hal.science/hal-02423786}

Submitted on 25 Dec 2019

HAL is a multi-disciplinary open access archive for the deposit and dissemination of scientific research documents, whether they are published or not. The documents may come from teaching and research institutions in France or abroad, or from public or private research centers.
L'archive ouverte pluridisciplinaire HAL, est destinée au dépôt et à la diffusion de documents scientifiques de niveau recherche, publiés ou non, émanant des établissements d'enseignement et de recherche français ou étrangers, des laboratoires publics ou privés. 


\title{
Dreams of Time, Times of Dreams: Stories of creation from roleplaying game sessions
}

\author{
Jerzy Kociatkiewicz \\ Essex Business School, University of Essex (affiliated with Graduate School for Social \\ Research, Polish Academy of Sciences at the time of publication) \\ kociak@kociak.org
}

\author{
"Space - The Final Frontier" \\ Star Trek
}

\begin{abstract}
Roleplaying games (RPGs) are an activity in which a group of people (called the players) creates and roleplays characters in a world devised by one other participant, called the Game Master, who describes the results of their actions as well as the actions themselves of everything and everybody else in this created world. The malleability of this world, coupled with the RPGs' social aspect, parallels the socially constructed reality which usually surrounds us. In this paper I collect a series of impressions from a few roleplaying sessions during which different groups of players attempted to construct new realities. In this sense, I examine the shared creation of reality out of empty space, exploring the potential inherent in roleplaying as a metaphor for organizing. I look for non-standard view-points on organizing which emerge from these sessions, and examine the process itself, not trying to pinpoint any regularities, but rather seeking the unusual and the sublime.
\end{abstract}

$$
\begin{array}{r}
\text { In the beginning, there was Wolf } \\
\text { And then there was Pig } \\
\text { And Wolf was a natural enemy of Pig } \\
\text { And it was good } \\
\text { And so our story begins } \\
\text { Mucky Pup „Little Pigs” }
\end{array}
$$

In the beginning, „there was chaos” (Kempiński, 1993: 232). Or perhaps „God created heavens and earth" (Genesis 1:1). So we are told, anyway. In the ancient mythologies have encountered, the myth of creation is always central, and it retains this place even after the arrival of the mythology of science. Myths bring people together and give them a sense of identity, being "a civilizational foundation for the whole of social organizing" (Margul, 1989: 9).
Their importance, however, is often seen as confined to primitive cultures, where they are thought to represent a pre-scientific form of knowledge. For example, the author quoted above regards them as "protophilosophy, and at the same time the protolaw, protoideology, protoliterature" (ibid.). Such a perspective erects highly debatable barriers between the realms of the scientific and the unenlightened, representing unsuccessful attempt to remove the grand narratives of science (Lyotard, 1979/1987) from the realm of mythology. Myths have the power of sparking imagination, an effect which lasts long after the belief in their truthfulness fades away. Ancient mythologies are to this day reworked into stories which might either be simply more or less imaginative retellings of 
ancient narratives (e.g. Frost, 1988), or which might use the mythical symbols or characters in different settings and plots (e.g. Zelazny, 1966/1989). Other authors write their own mythologies complete with tales of the world's origin, one of the most notable of which is J.R.R. Tolkien's Silmarillion (1977/1985).

Stories of creation speak about empty space, both as tales of the world emerging out of the primordial void, and as myths infusing meaning into the emptiness of the world perceived only as a shape. The process itself of describing the eradication of empty space serves to fill the void in making sense of reality, at least for as long as myths continue to be seen as sources of knowledge. Still, this paper does not aim to examination of ancient narratives, even if it is a venture into history.

History is the stories that we tell now. The process of organizing can be seen as one of contemporary myths, or stories, of creation. Burkard Sievers (1994) writes about organizations acting as sources of meaning for their participants - a role traditionally fulfilled by myths. Martin L. Bowles (1989) states even more explicitly that the mythical qualities of organizations are important aspect of their social function, and goes on (1993) to point out some of the mythical archetypes represented in today's organizations. My aim here is somewhat different. I attempt to expand the concept of the creation and maintenance of organizations (and reality), viewing it as a process of re-creating the myth of creation, of imbuing reality with meaning. In other words, I view organizations, and the process of organizing itself, as myths, or stories, negotiated and told jointly by their participants. They are related to the archetypal myth of creation because both speak of emergent order, of drawing up form, and of establishing new entities in the primordial void, or of re-creating entities in an attempt to stave off entropy. Seen this way, organizing appears as a mode of contemporary storytelling, and as such might be worth analyzing from the perspective of so-called roleplaying games (RPGs), an activity, or perhaps an art of the moderately regulated joint telling of stories. The name itself is something of a misnomer, as the word „game" implies a (more or less zero-sum) situation with winners and losers, while RPGs are actually more akin to the childhood play of make-believe. In RPGs, groups of people tell their own stories together, led by a person usually called the Game Master (GM), who creates and describes the world, or the setting, in which the story is to take place. The remaining participants, called the players, create personae (Player Characters, or PCs) for themselves, whom they subsequently roleplay (hence the name RPG), deciding on and describing the actions they want to take. While the GM is seen as playing the most important role, the success of the game, i.e. the vividness of the experience and the distinctiveness of the story, depends upon the joint effort of all the players (although not necessarily the cooperation of their characters).

One central ingredient in a typical roleplaying game is a set of rules, or "the system," used to define the actions allowed to PCs and for resolving conflicts among PCs, or between PCs and non-player characters (or NPCs), who are the remaining inhabitants of the setting, created and run by the GM. This is supposed to take care of the old childhood problem of conflicting ideas about reality („You're dead!” „No, I'm not!”), or rather to provide the GM, whose rulings are final ${ }^{1}$, with an easy way of determining the outcome of such conflicts. Too many rules, however, get in the way of telling a compelling story, and "in the end there is only one real rule (...): there are no rules" (Rein•Hagen, 1992: 79). A strict definition of boundaries would also form a framework leading further away from both the concept of the empty space and the idea of a roleplaying session as an act of creation. The latter metaphor was sketched by Sam Inabinet (1993), who described roleplaying as "a unique opportunity to hide the god of ourselves in the world of our own creation," (p.161) alluding to a cross-religious concept of god constituting "the world as a means of dissecting, examining and evaluating Himself" (p. 159).

This paper started out as a series of experimental roleplaying sessions which I have conducted, centred around the theme of creation, striving to bring out the richness of possibilities inherent in viewing organizing as such a social process of creation. In other words, the difference between these sessions and the more typical RPGs is that I did not attempt to explore the characters (and their creators) using the events of the game, concentrating instead on the free play of the collective imagination, using the roleplaying session as a tool for a social creation relatively unrestrained by any pre-set rules. If we accept Peter Berger and Thomas Luckmann's (1966/1983) argument that the reality we usually find ourselves in is socially constructed, we

${ }^{1}$ At least in theory. In practice, the players often try to negotiate with the GM regarding particular decisions, they consider these improbable or not in line with the story. 
can discern strong parallels between it and the reality of roleplaying games. Furthermore, as Richard Rorty (1980/1989) points out, we have no direct access to any objective reality "out there," and our ideas about it are determined and mediated by our language, communication, and contacts with other players in the grand game of reality. RPGs therefore come out as simply being much more explicit in their presentation of participants co-operating in creation than is the case in the 'usual' constructions of reality. I elaborate on this analogy elsewhere, together with Dariusz Jasiński (1996). Here I just wish to make the point that the ideas taking shape in the common imagination of the session participants need not be dismissed as distant and disconnected from our everyday experiences.

My explorations were concerned not only with player imagination, but also with the processes of organizing which took place during the sessions. Karl Weick (1969/1979: 3) describes organizing as „first of all grounded in agreements concerning what is real and illusory." The conversations between the characters can be seen as a way of reaching such agreements, or of finding them unnecessary.

I dare you to be real To touch a flickering flame The pangs of dark delight Don't cower in night fright Bauhaus "Double Dare"

In trying to explore organizing in empty space, I attempted to keep the rules and limitations imposed on the players to a bare minimum, leaving them as free as possible to create their own shared reality. In order to do so, I did not restrict the players' choices as to which characters they wished to play, nor did I specify how the session would look. Thus, the personae were chosen without any foreknowledge of how they were to be played. In the session itself, I introduced the characters, stating merely that they shared the same world, and asked if they had anything to say to each other. Some time later, dependent upon the intensity of the resulting exchange, I asked the players to take turns describing features of their world. Only one feature per turn was allowed, and they could not contradict anything that was said before. After 40 minutes to an hour of this, when the players began to grow less interested, I announced that the game would end after the next 3 rounds. Following this session, I asked the players for written descriptions of the created world, but only received such accounts from the participants in the first session.

The first three sessions ${ }^{2}$ (which in this paper I have called The Creation, The Narrative, and The Description) followed the scheme described above, while the fourth one (The Drama) was approached slightly differently. The change was not caused by any disenchantment with the original idea, or with the outcome of the first three sessions, but rather was intended to allow me to experiment with the social construction of narratives and not just states, implanting dynamism and change into the static creations I expected would arise in the course of the first three sessions, once again striving to restrict the players as little as possible. I announced the session would take the form of a story of creation, and asked the players (all of whom had participated in one of the previous sessions) to prepare characters involved somehow in creating the world. I offered examples of the Creator, the divine adversary, and the first human being. During the session, I asked the Creator (since one of the players chose that role) to describe how he created the world, and then interrupted only at specific points in time when the rest of the players had told me (prior to beginning the session) that their characters would appear. At this point I left the players to continue as they saw fit, and only stepped in to end the session when it began to get boring (not just to me as the observer, but, particularly, to the participants involved). Actually, I was asked at this point to let it continue a little longer, which, of course, I did.

$$
\begin{array}{r}
\text { You can't have everything } \\
\text { Why not? That's what it's there for } \\
\text { The Cassandra Complex „And you say” }
\end{array}
$$

Regardless of the goal of attempting to maximize the freedom of creation during these sessions, I found the use of at least some rules, both in this reality and in the reality of the game, necessary for a smooth transition between the two realities. I believe that a look at these limitations can help us understand better the constraints the players and their characters encountered in their shared process of creation.

My role as Game Master in this session clearly put me in a privileged position of power. After all, I had the very basic ability of determining the general outlook

\footnotetext{
${ }^{2}$ While I had conducted these first three sessions earlier, I analyzed them in detail only after finishing the fourth one; otherwise, I might have abandoned the idea of their static character.
} 
of the session, and of deciding which rules to waive and which to keep. This power was ever-present and, as one of the participants pointed out, manifested itself even in such seemingly trivial things as my ability to choose the location where the game took place. Less trivial was perhaps my decision to divide the players into particular groups for each session. I had no hidden agenda here, I simply preferred to keep players who knew each other together, and to form groups of three to five people in size. It is my experience that groups of such size account for the most interesting sessions, since in bigger groups each character receives too little common attention, and in smaller ones there is not enough interplay between characters. A point could also be made about the culture represented by the players, or even the language (Polish) in which the sessions took place, forming the basic framework and setting the boundaries for how far the created reality could differ from our usual one(s). Actually, the language used became a noticeable issue, especially in one session where one of the participants defined his character as "Nobody” and subsequently made extensive use of the double negative, correct in proper Polish. For example, „Nobody doesn't want to become somebody" is a correct sounding Polish sentence describing Nobody's intentions, rather than the English „Nobody wants to become somebody." The impact of this particular linguistic limitation (or of any other one, for that matter) on the behaviour of Nobody is hard to judge, but it does reveal the existence of a whole set of rules that might not be apparent at first sight.

There were indeed some rules in the game's reality, but they were caused rather by the encounter between the sets of meaning carried by the predefined character roles and the tabula rasa of the game reality. One such problem was the lack of any inherent power distribution. Regardless of character's description and his/her innate abilities, there were no mechanisms assuring any character his/her powers, so in one session the Creator's assumed supremacy over creation had to be negotiated. Another problem was that each character was supposed to be equally involved in defining the surroundings, regardless of ability or motivation to do so. Differentiation in involvement occurred only in one session where the characters did not conform to my idea of taking turns in describing the world, and in the other session I entitled The Drama, which followed a slightly different format.
All in all, though, I tried to exercise as little as possible both my power and my ability to define, and tried to keep out of the spotlight during the sessions themselves. During all of them, the players sat more or less in a circle facing each other, while I kept to the outside. Although I had the final word in determining the course of the session, I did not feel like a central figure in the proceedings, and the players (or characters) seemed to speak mostly to each other, not addressing their descriptions or comments to me. Once or twice I was asked to clarify my rules, which I did to the best of my ability, though when at some point the players would discuss the rules among themselves and reach a consensus, I chose not to intervene.

Why do people find each other strange? I can't tell one deranged from another deranged

Long Pig "Why do people find each other strange?"

There were not only differences due to the diversity of characters present, but to my delight, each session went down a totally different path, including the fundamental ways in which creation proceeded. I would like to present each of them in turn, and attempt to pinpoint their particular highlights.

In other words, it's showtime!

\section{The Creation}

\section{Dramatis Personae:}

The invisible hand of the market

Katarzyna, princess of $\mathrm{Amber}^{3}$, a vampire

Nobody

Pandora, goddess of the unknown

This was the first of the sessions, and the four participants varied widely as to their expertise in roleplaying, although all were familiar with the idea. The characters didn't seem to have much in common with each other (this session boasting probably the two most abstractly defined PCs), and did not say much when asked if there was anything they felt they could tell the rest of the group. The session came to life only after I asked the characters to describe the world they lived in together.

The characters usually followed their own list of features which they were introducing into the world,

${ }^{3}$ In Roger Zelazny's Amber series of books, Amber is the only true world, of which all the others are shadows. The princes and princesses of Amber are godlike beings capable of travelling between worlds.

This copy does not follow journal layout or page numbers. Originally published in Studies in Cultures, Organizations and Societies 
although on a few occasions, some powerful statement would elicit a response from the rest of the group. One such example was the introduction of death, which was claimed by other players to be one of the concepts the inhabitants of the world used to limit themselves, and which should be representable as two parallel straight lines. The notion of time was also elaborated on, and was said to flow sideways, and not forwards or backwards.

Most of the time, though, the characters contented themselves with enumerating the elements of the world, rather than describing them in detail, and even in the cases of time and death, no further elaboration followed the rather cryptic characterizations quoted above. For example, one character introduced the existence of over 5 billion genders, but the notion was left at that, without any explanations as to the consequences of it. Generally, the characters seemed to mention whatever they felt to be the key features of the world, rather than trying to construct a coherent whole. Only a few times were the described features restrictive. This was the case with the pronouncement that only the laws of economy were beautiful, or that there existed only one best way to solve problems.

This was also the only session during which my role was questioned. At one point one of the characters turned to me and asked who I was, at which point I denied my existence in the game reality. In the notes on the session that I received after the game, another player described me as the deist god, unreferenced in the process of creation.

\section{The Narrative}

\section{Dramatis Personae:}

A little green alien

Legion, the spirit of rebellion

A spirit living in people's dreams

Winnie the Pooh

Here the group of consisted of experienced roleplayers who were members of a gaming club and were thus accustomed to roleplaying together. All characters except the dream-spirit, who was content to watch and comment on the developing story, had clearly defined goals they wished to achieve. Thus, the green alien had definite instructions to prepare the planet for conquest by the galactic empire. Legion wanted to destroy the creator. Winnie the Pooh wished for a peaceful life in "his” forest, but was also curious about all the newcomers. These plans were already known and the characters were on the outlook for possible allies and enemies when I asked them to start describing their world. At this point, rather than abandoning the plot that started to form, the players continued to develop it, using the descriptive form to actually construct a narrative, while the various features of the world appeared only when significant to the story.

This was the only session where the characters clearly developed their own, unique perceptions, and felt no need to negotiate a common perspective on the surrounding world. Each took care to recapitulate the descriptions of his predecessors, using his own language and references. Thus, when Winnie the Pooh stated that it was 10:15, the alien, always on the lookout for powerful technology, remarked that the planet's inhabitants have a device capable of stopping the flow of time. Since all characters' proclamations held true through the whole session, Winnie's statement caused the time to stop at 10:15. At another point, the dream-spirit spoke about a blanket of childhood memories used by the dreamer who created the whole reality. Legion identified this blanket as Winnie's woollen muffler, exposing the Pooh as the dreaded creator Legion rebelled against. The session turned into an elaborate game where the three characters vied for power, while a detached dreamspirit interpreted everything as the psychoanalytically meaningful dream of some troubled person. The ability to describe the setting was clearly used as a tool for gathering power, but this was evident only at the player level - the characters were all convinced they were just describing the already existing universe. As all the players clearly sided with their own characters, the distinction between the consciousness of the character and the player was at best blurry, and it would perhaps be better to speak of reality description as a constantly utilized, though not fully controlled, tool for gaining power. Character statements had to sacrifice some possible gains in power in order to keep in touch with the general worldview of that character.

All characters ensured their immortality through statements ranging from "this is just a dream, so it cannot affect me” to "Chris is strong and he can protect me from any harm." This doesn't mean that there was no struggle and no shifts of power. At the end of the session, Winnie was clearly losing to an uneasy alliance between the green alien and Legion. 
Here the ability to define reality was clearly constituted by at least two characters as a tool for power, a definition which the other characters readily accepted, even though the dream spirit chose not to get involved in the power games. This definition was also used for telling a common story, as the session was very clearly narrative, which apparently required neither a shared understanding of the surroundings nor the flow of time. The aspects of the world gained significance only in relation to the events taking place in the described setting.

\section{The Description}

\section{Dramatis Personae:}

A stone angel

A trans-dimensional mushroom

A hive mind consisting of 7 people

This session differed from the others in that only three players were present, though the beginning of the game looked pretty much like The Creation session. The characters didn't seem to have much in common, and as the stone angel was immobile, and the hive mind did not wish to travel away from the castle where it (they?) normally lived, the meeting of these two was pronounced to be quite improbable, even though the hive mind began to exhibit some curiosity about such a meeting. However, when I asked the players to describe their common world, once again the outlook of the session changed.

The stone angel (who was omniscient, except for knowledge of his future) took a leading role in describing the universe, not so much by overtly forcing his definitions upon the others, but rather by undertaking the task of collecting the available data and constructing a coherent picture from the scraps provided. The mushroom readily joined in creating the description, but the hive mind claimed to have little knowledge of the surrounding world, always keeping to its castle. Because of that, the castle figured centrally in all of its statements, and the stone angel started referring to the hive mind as a castle - a label that at first seemed distasteful to the being thus described, but which it later grudgingly accepted. This was the only time such symbolic violence took place during these sessions, where a character was transformed by outside pressure.

Another feature of this session was that, instead of the participants adding aspects to the world one by one in their consecutive turns, a formally unstructured creation of the world took place, accomplished almost single-handedly by the stone angel. The mushroom did make some contribution, whereas the castle mainly refrained from participation. The consecutive order of speaking, which I had attempted to impose, was ignored in favour of collective decisions. Once again, the cooperation took place mostly between the angel and the mushroom, with the hive mind keeping to its castle and providing only very scant information on any other features. Of all the sessions, this offered the most general and descriptive view of the world. It was also the most uniform one, since all its features were socially agreed upon, and not open to personal interpretation, as was the case in the other sessions.

\section{The Drama}

\section{Dramatis Personae:}

The author of Genesis

The Creator

An independent being

Pandora, goddess of imperfection

This session took on a different form from those of the other three. The players were asked to create a story rather than describe a static setting. It also brought together some of the participants in the Creation and the Narrative sessions. One player even decided to play the same character, although cast into a somewhat different role this time. In this session, the involvement of the different characters in the story varied considerably. The Creator, and the independent being who came to life somehow in the course of creation, easily took centre stage, while the author of Genesis had the least impact on the story. The narrative itself came to rely very strongly on the main characters' vivid personalities, and was more of a showdown between a possessive, imperfect, and very defensive Creator and an individualistic being wishing to participate in the poetics of the newly created world. The world itself, or its shape, wasn't an important issue here. Actually, the Creator did not pay much attention to it until things began to get out of hand. The unplanned appearance of this being he could not control sent him into a fit of rage, and he actually destroyed his creation in order to replace it with a new one. This didn't banish the troublesome being, 
however, which was a source of both anger and joy to the Creator, who relished the break from his loneliness, even as he despised the obvious proof of his imperfection. This whole time, Pandora contented herself with pointing out all the failings apparent in the reality, while the author of Genesis kept pretty much to announcing the titles of the books s/he planned to write.

It was in this session that the participant playing the Creator turned to me to enforce his omnipotence in the game reality. When I failed to respond immediately, he switched to a conversational mode of establishing his power, ceding his sovereignty over the independent PC, but insisting on keeping it over the rest of his creation (although he did not try to directly influence any other PCs). Since the initial commanding tone was clearly tied to the very power structure the Creator was trying to establish only at that moment, it could not itself be used for establishing the structure which served as its power base.

$$
\begin{array}{r}
\text { I put my hand into the roaring flames } \\
\text { I felt the pain as it started to burn } \\
\text { I've done the same thing over and over again } \\
\text { As if I never ever wanted to learn } \\
\text { New Model Army „Fate” }
\end{array}
$$

I already mentioned that I received written descriptions of the created world from the participants in the first session. Curiously enough, all of them, and none of the others, responded to my plea for such a summary. Here I treat the characters, not the players, as what Umberto Eco (1994/1995) calls the model authors of the texts. Thus the reports, which did not keep only to what was said during the session, constitute yet another form of creation, of filling in the empty space. The form of these writings varied. Nobody (the character) wrote a stream of consciousness letter signed "Somebody," while The invisible hand of the market provided a structured list of the existing groups of concepts, and also described her root metaphor as that of bibliography. The other two characters wrote comprehensive accounts of the world, making sense of and connecting the features mentioned during the session. Katarzyna also described in detail the intricacies of her own motivation, which she did not make known during the session.

While the list of concepts defined during the session and mentioned in the reports varied, some were common to all the texts. Thus, all the authors mentioned the high number of genders existing in the world (over 5 billion), and both Pandora and Nobody elaborated on this subject. One of them provided an example of the gender of an elephant being different from the gender of a cockroach, while the other interpreted it as every person in the world being of different gender.

$$
\begin{aligned}
& \text { The road goes ever on and on } \\
& \text { Down from the door where it began } \\
& \text { Now far ahead the road has gone } \\
& \text { And I must follow if I can } \\
& \text { J.R.R. Tolkien „Lord of the Rings" }
\end{aligned}
$$

This journey through these different worlds draws now to a close, and we are left wondering what we have gained by encountering their intricacies. I have already confessed to my fascination with the encountered diversity, and to me it is justification enough. Moreover, it seems that this is not the only way that the described sessions touch the issues relevant to the discourse of organization studies.

I believe that these sessions have something to offer our understanding of organizational reality, due to the very diversity which they used to fill the (almost) empty space in which they began. The diversity encompassed not only the features of the world created by the characters, but perhaps most importantly, the ways such creation took place, the emerging rules of interaction, and the attitude towards reaching a shared viewpoint. I can also claim some success in abandoning the strict restraints of the rules, which I found totally unexpected. It is thus interesting to note that, while The Drama session was originally intended by me to be a narrative one, it became quite static when the participants decided that the storyline was not the most important issue. The story did have its day, though, in The Narrative, which I assumed would have been a static description. In the same session, no agreement was needed as to the shape of the universe. The actors could act according to their own motivations and assessment of the situation, and were perfectly well „understood" by other actors who saw the situation in an entirely different way. This interfered neither with communication nor with cooperation. Conversely, in The Description, the insistence on a unified worldview resulted in the emergence of oppression. From this, it could perhaps be concluded that at the heart of organizing need not lie agreement on what is 'real' or 'illusory' as postulated by Karl Weick, but rather on what is significant. Organizations resulting from 
this approach could be viewed as networks of actants (Latour, 1993) connected by the bonds of mutually perceived significance.

Let us now reconsider two of the "down-to-earth" issues which appeared during the sessions, gender and power, which came up during the sessions. These issues in particular ran a very close parallel to everyday organizing. But what is interesting is not so much how closely the issues of gender and power in the sessions resembled those in "real" organizations. Rather, it was the unexpected shapes those concepts took on. There was the multiplicity of genders (The Creation) much like the wildly varying genders (or gender archetypes) which we can meet in everyday organizations, even though there the official gender count is limited to two. Power was construed alternately as the main goal (the Narrative), as a side effect of descriptive zeal (the Description), and as a troublesome privilege (the Narrative).

Taking up these issues in our usual reality, Silvia Gherardi (1995), describes diverse visions of femininity encountered in contemporary western organizations. Incidentally, she chooses a mythological approach as well, identifying these archetypes with the Greek goddesses Artemis, Athena, Demeter, Hera, Hestia, and Persephone, each representing a different female archetype. Perhaps speaking of male and female archetypes here is in itself an unnecessary generalization, and it would be better to stick to the framework used during the session, viewing all these Goddesses as representing different genders. In this way we can stress the discretionary character of presenting gender as dichotomy, an approach congruent with Bronwyn Davies' (1989) observations on the institutionalization of gender dichotomy and gendered behaviour in pre-school children as well as with the language of The Creation session. The concept of power can likewise show many faces, not only during roleplaying sessions, but also in organizational reality, as Barbara Czarniawska-Joerges' (1990) study shows, power can be viewed alternately as a process, as an intricate game, as a source or instrument of oppression, or as an expression of irrationality, given both positive and negative connotations.

While this multiplicity of approaches may be seen as in severe need of systematization, I prefer to view this variety as a testimony to the arbitrariness of all „natural” or „obvious” divisions, concepts, or understandings. As such, these sessions serve to illustrate Paul Feyerabend's point that:

[f] or every statement, theory, point of view believed (to be true) with good reasons there exist arguments showing a conflicting alternative to be at least as good, or even better (1987/94: 76)

In any case, the sessions were not meant to present an exhaustive list of available methods for organizing, nor to be taken as guidelines, but rather as a glimpse at the vast potential inherent in experimenting with rules. It is in this role that I hope they can provide inspiration. One way of viewing these sessions is as parables, in which the reader is left with the task of deciding on an interpretation. As such they can easily be understood to represent contemporary organizing processes, even though their apparent subjects remain far removed from everyday reality. Nevertheless, they seem to me a rich source of what Pierre Guillet de Monthoux and Barbara Czarniawska call "tacit knowledge: they describe knowledge without analysing it, thus tapping on more than an explicit message characteristic for paradigmatic teaching" (1994:9). Such tacit knowledge is closer to experience than to explanation. Consequently, the links between the described sessions and the usual context of organizing need not be sought on the level of explicit references.

Yet to step out beyond linear rationality, which Gibson Burrell (1997) presents as being quite capable of causing literal death, and instead to open up organizational discourses to ambiguity, ambivalence, and poetics (Höpfl, 1995), we need to look not only at organizations as the knowledge base on organizing. Monica Lee (1997), for example, draws enlightening insights from observing and raising sheep, and roleplaying sessions can, as I hope I have demonstrated, provide another source of reflective inspiration. Drawing on roleplaying can be further justified by the greater degree of freedom of experimentation with explicit and implicit rules which is available in RPGs than in the usual organizational realities.

My final reflection will be to point out the one feature missing in these sessions, the inclusion of which might have changed them quite dramatically even if it would not have undermined the insights they provided: The possibility to unweave introduced definitions. Fortunately we are not denied this possibility, and it is still for the taking as yet another empty space. This means we have come full circle now, and the empty space still remains

The Final Frontier

This copy does not follow journal layout or page numbers. Originally published in Studies in Cultures, Organizations and Societies 


\section{References}

Berger, Peter L. and Thomas Luckmann (1966/1983) Spoteczne tworzenie rzeczywistości. (The Social construction of reality) Warszawa: PIW.

Bowles, Martin L. (1989) 'Myth, meaning and work organization,' Organization Studies, 10(3): 405421.

Bowles, Martin L. (1993) 'The gods and goddesses: Personifying social life in the age of organization,' Organization Studies, 14(3): 395418.

Burrell, Gibson (1997) Pandemonium. London: SAGE.

Davies, Bronwyn (1989) Frogs and snails and feminist tales. Sydney: Allen and Unwin.

Eco, Umberto (1994/1995) Sześć przechadzek po lesie fikcji (Six walks in the fictional woods). Kraków: Znak.

Feyerabend, Paul (1987/94) Farewell to reason. London: Verso.

Frost, Gregory (1988) Remscéla. New York: Ace.

Gherardi, Sylvia (1995) Gender, symbolism and organizational cultures. London: SAGE.

Guillet de Monthoux, Pierre and Barbara Czarniawska-Joerges (1994) 'Introduction: Management beyond Case and Cliché' in: Barbara Czarniawska-Joerges and Pierre Guillet de Monthoux (eds.) Good novels, better management: Reading organizational realities. Chur: Harwood, pp. 1-16.

Höpfl, Heather (1995) 'Organisational rhetoric and the threat of ambivalence,' Studies in Cultures, Organizations and Societies, 1(2): 175-187.

Inabinet, Sam (1993) 'Roleplaying and the hidden god,' The Vampire players guide. Stone Mtn: White Wolf, pp. 159-161.

Jasiński, Dariusz and Jerzy Kociatkiewicz (1996) 'The roles, the rules, and the reality,' paper presented at the Symbols of Oppression Conference, Bolton Institute, April.
Kempiński, Andrzej M. (1993) Stownik mitologii ludów indoeuropejskich (Dictionary of the mythology of Indoeuropean peoples). Poznań: SAWW.

Latour, Bruno (1993) 'On technical mediation,' Working paper, Lund University.

Lee, Monica (1998) 'Sheep and the consumptive identity,' paper presented at the Production of Consumption Conference, Bolton Institute, April.

Lyotard, Jean-François (1979/1987) The postmodern condition: a report on knowledge, Manchester: Manchester University Press.

Margul, Tadeusz (1989) Mity z pięciu części świata (Myths from five parts of the world), Warszawa: Wiedza Powszechna.

Rein•Hagen, Mark (1992) Vampire: the Masquerade, Stone Mtn: White Wolf.

Rorty, Richard (1980/1989) Philosophy and the mirror of nature, Oxford: Blackwell.

Sievers, Burkard (1994) Work, death, and life itself: Essays on management and organization, Berlin: De Gruyter.

Tolkien, J.R.R. (1977/1985) Silmarillion (The Silmarillion), Warszawa: Czytelnik.

Weick, Karl E. (1969/1979) The social psychology of organizing, Reading: Addison-Wesley.

Zelazny, Roger (1966/1989) This Immortal, New York: Baen.

This copy does not follow journal layout or page numbers. Originally published in Studies in Cultures, Organizations and Societies 